12,03

\title{
Локализация носителей заряда в квантовых ямах InGaN/GaN, ограниченная объемным зарядом
}

\author{
(C) Н.И. Бочкарева, Ю.Г. Шретер \\ Физико-технический институт им. А.Ф. Иофрфе РАН, \\ Санкт-Петербург, Россия \\ E-mail: n.bochkareva@mail.ioffe.ru
}

Поступила в Редакцию 12 ноября 2021 г.

В окончательной редакции 12 ноября 2021 г.

Принята к публикации 13 ноября 2021 г.

\begin{abstract}
Механизм туннелирования носителей заряда через потенциальные стенки квантовой ямы InGaN/GaN в $p-n$-структурах исследуется методом туннельной спектроскопии глубоких центров. На зависимостях от прямого смещения интенсивности и спектрального сдвига полосы фотолюминесценции из квантовой ямы обнаруживается ряд горбов при тех же смещениях, что и ряд горбов на зависимостях прямого туннельного тока и фототока, генерируемого оптически инжектированными носителями, туннелирующими из квантовой ямы в барьеры. Эти туннельные эффекты находят объяснение в рамках модели локализации носителей в квантовой яме, связывающей туннельную проницаемость потенциальных стенок квантовой ямы с плотностью объемного заряда глубоких центров окраски в барьерах ямы и ее изменением при оптическом возбуждении и прямом смещении $p-n$-структуры.
\end{abstract}

Ключевые слова: нитрид галлия, квантовая яма, фотолюминесценция, туннельная спектроскопия глубоких центров, примесные центры окраски.

DOI: 10.21883/FTT.2022.03.52099.241

\section{1. Введение}

В структурах с квантовыми ямами InGaN/GaN, являющихся базовым элементом источников твердотельного освещения $[1,2]$, высокая квантовая эффективность излучательной рекомбинации достигается вопреки высокой плотности структурных дефектов решетки (дислокаций, дефектов упаковки), а также точечных дефектов и их комплексов, образующих более глубокое, чем в аморфном $\mathrm{Si}$, распределение локализованных состояний в запрещенной зоне $\mathrm{GaN}\left(E_{g, \mathrm{GaN}}=3.42 \mathrm{eV}\right.$ при $\left.300 \mathrm{~K}\right)$ [3]. Нитрид галлия позволил не только изменить устоявшиеся представления, что высокая плотность дислокаций исключает приемлемую работоспособность оптоэлектронных приборов [1], но и продемонстрировать возможность реализации в материале с „грязной“ запрещенной зоной квантовой эффективности, достигающей $86 \%$ [2].

Уже ранние экспериментальные исследования показали доминирующую роль дефектов в туннельном механизме протекания тока через потенциальные барьеры в светоизлучающих и фотовольтаических наноструктурах, а также в затворах полевых транзисторов на основе $\mathrm{GaN}$ [4-6]. Однако механизм туннелирования с участием дефектов и его роль в критически важных для развития твердотельного освещения проблемах, включая проблемы падения квантовой эффективности в мощных оптоэлектронных приборах и увеличения их долговечности, до сих пор изучены недостаточно.

Теоретически туннелирование с участием дефектов (trap-assisted tunneling, hopping) через барьер, создавае- мый запрещенной зоной, рассматривается на основе подходов, использовавшихся ранее для описания туннельных токов утечки в диэлектриках и избыточного тока в туннельных диодах и неидеальных гетеропереходах. которые предполагали туннелирование через дискретные центры [7], примесную зону [8] или через центры с однородным энергетическим распределением [9]. Однако эпитаксиальные слои GaN и квантовые ямы InGaN/GaN характеризуются глубокими хвостами локализованных состояний, присущими неупорядоченным и частично разупорядоченным средам, в которых высокая плотность состояний позволяет носителям туннелировать прыжками между локальными центрами.

Так, широкие спектры излучения квантовых ям InGaN/GaN хорошо описываются в принятой для неупорядоченных твердых растворов [10] модели термализации экситонов за счет туннельных переходов с участием фононов между состояниями экспоненциальных хвостов, связываемых с композиционными флуктуациями ширины запрещенной зоны твердого раствора $\mathrm{In}_{x} \mathrm{Ga}_{1-x} \mathrm{~N}$ [11]. В эпитаксиальных слоях $\mathrm{GaN}$ прыжковая проводимость по локальным примесным центрам вносит значительный вклад в электронный транспорт даже при комнатной температуре и доминирует при понижении температуры [12].

Непрерывный энергетический спектр дефектов в запрещенной зоне $\mathrm{GaN}$ имеет особенности, связанные с примесными зонами глубоких центров, включающих кислородо- и водородозамещенные вакансии. Комплексы точечных дефектов обусловливают широкие полосы внутрицентрового поглощения и фотолюминесценции 
(ФЛ) в видимой области спектра (центры окраски), а также в ближней ИК- и ближней УФ-областях (т.н. ИК- и УФ-центры окраски) [11,13,14]. Малый стоксов сдвиг между длинами волн возбуждения и излучения внутрицентровой ФЛ в $\mathrm{GaN}$ свидетельствует, что возбужденные носители термализуются за счет туннельных переходов с участием фононов между центрами локализации. Медленная кинетика затухания ФЛ [11] отражает экспоненциальное затухание скорости туннелирования в более глубокие состояния с меньшей плотностью. Кинетика, характеризуемая растянутой экспонентой, наблюдалась и для переходных прямых токов в $p-n$-структурах с квантовыми ямами $\mathrm{InGaN} / \mathrm{GaN}$ [15]. Следует ожидать, что скорость туннельного переноса заряда через барьер при электрической инжекции ограничивается частотой прыжков вблизи квантовой ямы, в слое с наименьшей плотностью локальных центров на длине туннелирования. Это дает возможность применить для изучения спектра дефектов метод туннельной спектроскопии Эсаки, дающий информацию об уровнях энергии в твердых телах: в тонких слоях изоляторов и узких полупроводниковых $p-n$-переходах [7]. Экспериментальные вольтамперные характеристики прямосмещенного $p-n$-перехода анализируются в этом методе в предположении, что скорость туннелирования определяется плотностью пустых конечных состояний на границе перехода. В то же время в случае высокой плотности локальных центров вероятность туннельного перехода через треугольный потенциальный барьер в сильном электрическом поле, рассчитанная Келдышем [16], может существенно уменьшаться в результате перезарядки локальных центров и уменьшения плотности объемного заряда и напряженности поля.

В настоящей работе мы представляем экспериментальные данные, касающиеся механизма туннельного тока и люминесценции в $p$ - $n$-структурах с одиночными квантовыми ямами InGaN/GaN. Зависимости туннельного тока от прямого смещения обнаруживают интересные особенности. Максимумам туннельного тока на „темновых“ $I-V$-кривых соответствуют минимумы туннельного тока при оптическом возбуждении, а также горбы на зависимостях интенсивности и спектрального сдвига полосы ФЛ из квантовой ямы от смещения. Эти наблюдения позволяют нам предложить модель локализации носителей в квантовой яме, связывающую туннельную проницаемость потенциальных стенок ямы с плотностью объемного заряда глубоких центров и ее изменением при оптическом возбуждении и прямом смещении $p-n$-структуры.

\section{2. Эксперимент и экспериментальные результаты}

Для исследования выбраны два типа светоизлучающих $p-n$-структур с одиночной квантовой ямой
InGaN/GaN толщиной $30 \AA$, излучающих в синей области спектра с пиковой энергией излучения $h v_{p}=2.65 \mathrm{eV}$ $\left(v_{p}=465 \mathrm{~nm}\right)$ при номинальном токе $I=20 \mathrm{~mA}$ (площадь структур $10^{-3} \mathrm{~cm}^{2}$ ). Структуры отличаются величиной внутренней квантовой эффективности электролюминесценции (ЭЛ), составляющей в структурах, обозначенных как А и В, 60 и 40\% соответственно и уровнем туннельных токов утечки, составляющими $\sim 1 \mathrm{nA}$ и $3 \mu \mathrm{A}$ соответственно, при смещении $V_{t h}=2.2 \mathrm{eV}$, необходимом для детектирования пороговой интенсивности ЭЛ. Детали структур приведены в $[17,15]$. Как показали измерения вольтфарадных характеристик, в наноструктурах $\mathrm{A} n$ - и $p$-области сильно легированы $\left(>3 \cdot 10^{18} \mathrm{~cm}^{-3}\right)$, но в слое $n$-GaN есть слабо легированная $\left(7 \cdot 10^{16} \mathrm{~cm}^{-3}\right)$ область шириной $\sim 120 \mathrm{~nm}$, граничащая с квантовой ямой. В наноструктурах В $n$-область легирована значительно сильнее $\left(10^{18} \mathrm{~cm}^{-3}\right)$, чем $p$-область $\left(\sim 2 \cdot 10^{17} \mathrm{~cm}^{-3}\right)$.

Измерения вольт-амперных характеристик проведены с помощью источника-измерителя тока и напряжения Keithley 238. Подзонное оптическое возбуждение осуществлялось светом вольфрамовой лампы накаливания. Фотолюминесценция возбуждалась $\mathrm{He}-\mathrm{Cd}$ лазером мощностью $20 \mathrm{~mW}$ на длине волны $325 \mathrm{~nm}$ $(h v=3.81 \mathrm{eV})$. Спектры ФЛ регистрировались на спектрометре AvaSpec-2048.

При подзонном возбуждении $p$-n-структур с квантовой ямой InGaN/GaN c энергией фотонов $E_{g, \mathrm{GaN}}>h v>h v_{p}$ оптически генерированные носители туннелируют из квантовой ямы и, разделяясь в поле $p-n$-перехода, генерируют фототок (рис. 1) [11,18].

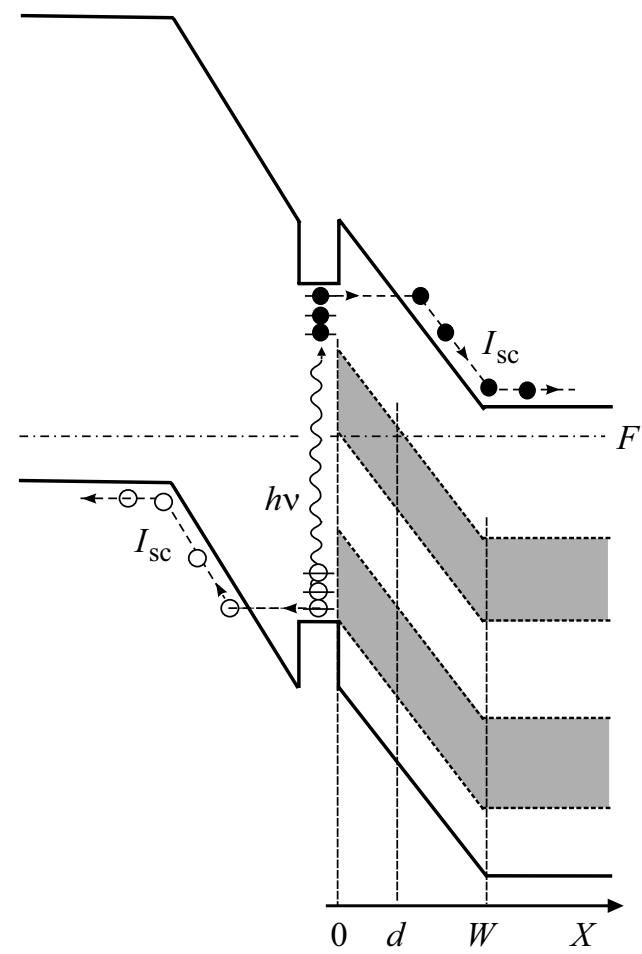

Рис. 1. Схема энергетических зон $p-n$-структуры с квантовой ямой $\mathrm{InGaN} / \mathrm{GaN}$. 


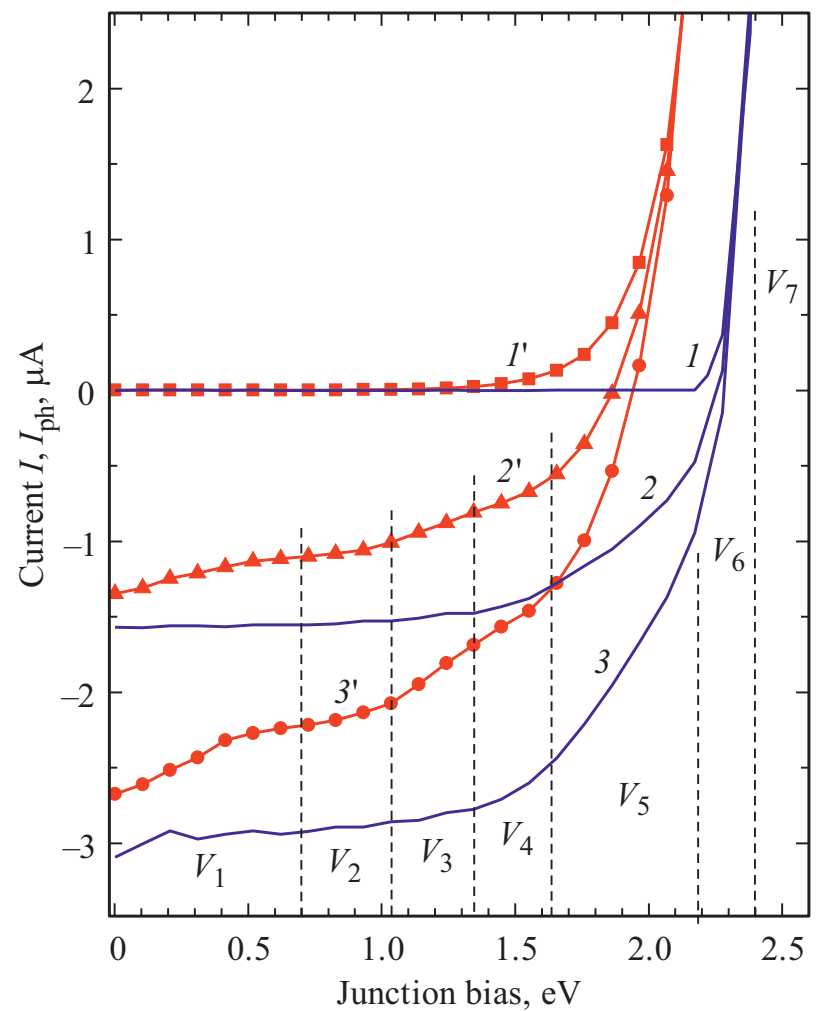

Рис. 2. Зависимости тока от прямого смещения для структур А $(1-3)$ и В $\left(1^{\prime}-3^{\prime}\right)$, измеренные в ,темноте“ $\left(1,1^{\prime}\right)$ и при подзонном оптическом возбуждении $\left(2,3,2^{\prime}, 3^{\prime}\right)$. Мощность возбуждения, $\mathrm{mW} / \mathrm{cm}^{2}: 2,2^{\prime}-50,3,3^{\prime}-100$. Штриховыми линиями отмечены интервалы смещений $V_{1}-V_{7}$, обозначенные на рис. $3, a$.

Зависимости тока от прямого смещения $V$ в электронвольтах $\left(V \equiv F_{n}-F p-\right.$ разность электронного и дырочного уровней Ферми) для $p-n$-структур А и В, измеренные в „темноте“, т.е. в отсутствие оптического возбуждения, и при подзонном оптическом возбуждении, представлены на рис. 2. На рис. $3, a, b$ зависимости темнового тока $I$ от прямого смещения показаны в полулогарифмическом масштабе (кривые 1 ).

В структуре А прямой темновой ток сначала резко возрастает до максимального значения $I_{p}=0.06 \mathrm{nA}$ при смещении $V_{p}=0.31 \mathrm{eV}$, затем, после небольшого падения тока в области с отрицательной дифференциальной проводимостью, наблюдается еще один относительный максимум (рис. 3, a, кривая 1). При дальнейшем увеличении смещения наблюдаются три „горба“ туннельного тока, причем ток между горбами монотонно растет с ростом смещения. При смещении $V=1.65 \mathrm{eV}$ избыточный туннельный ток начинает резко расти и превышает по величине пиковый ток $I_{p}$. Наиболее резкий ступенчатый рост туннельного тока наблюдается вблизи порогового смещения $V_{t h}=2.2 \mathrm{eV}$. В структуре В вблизи нулевого смещения темновой ток равен току в структуре А, но с увеличением смещения ток растет приблизительно по экспоненциальному закону и вблизи порогового смеще- ния превышает темновой ток в структуре А более чем на три порядка (рис. $3, b$, кривая 1$)$.

Отметим, что темновая $I-V$-характеристика структуры А по форме имеет много общего с $I-V$-характеристиками узких туннельных переходов, в которых обе стороны перехода легированы до вырождения. Максимум туннельного тока $I_{p}$ при смещении $V_{p}=0.31 \mathrm{eV}$ напоминает аналогичный максимум в туннельных переходах, обусловленный межзонным туннелированием. Максимум на спаде пика туннельного тока наблюдался и в туннельных переходах, где он связывался с избыточным туннельным током через глубокие центры дефектов [19], как и токовые горбы в долине $I-V$-характеристики. В структуре А амплитуда туннельного токового максимума очень мала, но отношение пикового тока к току долины, являющееся одним из показателей качества туннельного перехода, высокое: $I_{p} / I_{v}=10$.

Из рис. 2 видно, что в $p$ - $n$-структурах не выполняется правило аддитивности идеального фотодиода или солнечного элемента, согласно которому фототок $I_{p h}=I_{s c}+I$ равен сумме фототока короткого замыкания $I_{s c}$, текущего в обратном направлении $\left(I_{s c}<0\right)$ и не зависящего от напряжения, и прямого тока $(I>0)$, не зависящего от освещения. Сопоставление кривых $I_{p h}-V$ и $I-V$ показывает, что фототок уменьшается с ростом смещения быстрее, чем растет темновой прямой ток.

Характер изменения фототока с ростом прямого смешения иллюстрируется на рис. 3, $a, b$, где показаны в полулогарифмическом масштабе зависимости $I_{o p t}(V)=I_{p h}-I_{s c}$ для структуры В при различных уровнях возбуждения (рис. $3, b$, кривые 2-4) и для структуры А при высоком уровне возбуждения (рис. 3, $a$, кривая 4). При меньших уровнях возбуждения фототок в структуре А увеличивается до $I_{\max }$ при увеличении смещения до $\sim 0.4 \mathrm{eV}$, и характер изменения фототока в этих условиях иллюстрируется кривыми $I_{\text {opt }}(V)=I_{p h}-I_{\max }$ (рис. 3, $a$, кривые 2, 3).

Подзонное оптическое возбуждение приводит к сильному увеличению туннельного тока, причем в структуpe А в области горбов темнового туннельного тока на $I-V$-кривых наблюдаются провалы светового туннельного тока $I_{\text {opt }}$ (рис. 3,a, кривые 2,3). С повышением уровня возбуждения на кривых $\lg I_{\text {opt }}(V)$ структуры В становятся все более различимы ступени в области тех же смещений, что и горбы темнового тока в структуре А (рис. $3, b$, кривая 4 и рис. 2 , кривая $3^{\prime}$ ).

При межзонном возбуждении излучением лазера $(h v=3.81 \mathrm{eV})$ в структурах наблюдается фотолюминесценция из квантовой ямы и фототок. На рис. 4 представлены зависимости от прямого смещения темнового тока $I(V)$ и зависимости $I_{\text {opt }}(V)=I_{p h}(V)-I_{s c}$, характеризующие уменьшение фототока с ростом смещения при межзонном возбуждении, а также зависимости от смещения интенсивности фотолюминесценции $I_{\mathrm{PL}}(V)$ и пиковой энергии фотолюминесценции $h v_{\mathrm{PL}}(V)$ для структуры В. 

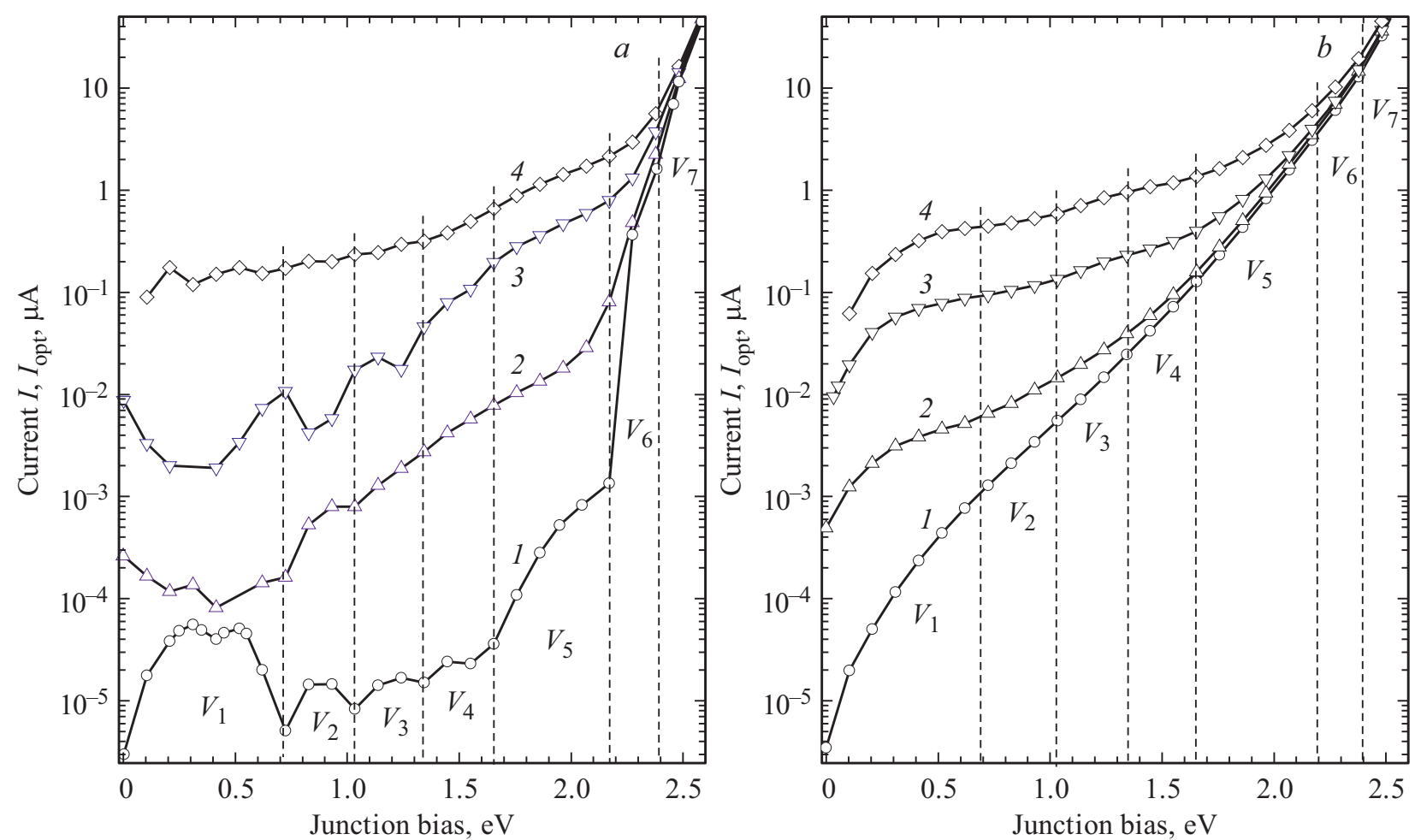

Рис. 3. Зависимости тока от прямого смещения для структур А $(a)$ и В $(b)$, измеренные в „темноте“ $(1)$ и при подзонном оптическом возбуждении (2-4). Мощность возбуждения, $\mathrm{mW} / \mathrm{cm}^{2}: 2-1,3-50,4-100$. Штриховыми линиями отмечены интервалы смещений $V_{1}-V_{7}$, в которых наблюдаются горбы и ступени на кривой $1(a)$.

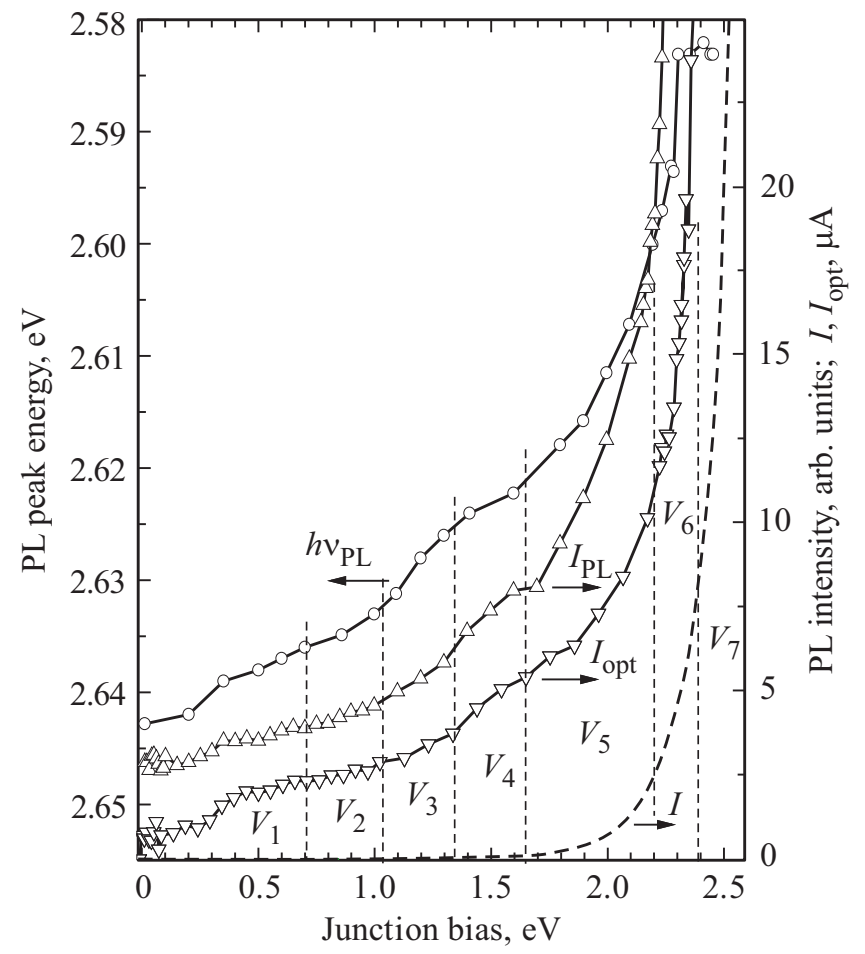

Рис. 4. Зависимости прямого тока $I_{\text {opt }}$, интенсивности фотолюминесценции $I_{\mathrm{PL}}$ и пиковой энергии фотолюминесценции $h v_{\mathrm{PL}}$ при лазерном возбуждении и прямого тока в отсутствие возбуждения $I$ от прямого смещения для структуры В. Штриховыми линиями отмечены те же интервалы смещений $V_{1}-V_{7}$, что и на рис. $3, a . T=300 \mathrm{~K}$.
Как видно из рис. 4, различимые горбы на кривых $I_{\text {opt }}(V)$ при межзонном возбуждении (кривая 2), наблюдаются в области тех же смещений, что и при подзонном возбуждении (рис. 2 , кривая $3^{\prime}$ и рис. $3, b$, кривая 4 ). Из рис. 4 также видно, что интенсивность и красный сдвиг пиковой энергии фотолюмнесценции из квантовой ямы увеличиваются с ростом прямого смещения быстрее в тех интервалах смещений, в которых быстрее уменьшается фототок.

\section{3. Обсуждение результатов}

Туннельная проницаемость и туннельная проводимость потенциального барьера. В простейшей форме туннельная проницаемость потенциального барьера высотой $\varphi$, определяющая вероятность туннелирования носителя заряда из занятого начального состояния с энергией $E$ в пустое конечное состояние с той же энергией, имеет вид [16]:

$$
D=\exp \left(-\frac{\pi \delta}{2 \sqrt{2 \hbar}} \sqrt{2 m^{*} \varphi}\right),
$$

где $\delta=\varphi / F=\left(\varepsilon / q^{2} N_{t}\right)^{1 / 2}$ - ширина барьера, $F$ напряженность электрического поля, $N_{t}-$ плотность ионизованных примесей, $q-$ заряд электрона, $\varepsilon-$ диэлектрическая проницаемость, $m^{*}$ - приведенная эффективная масса электрона и дырки. 
Дифференциальная туннельная проводимость барьера $g_{\text {tun }}$ пропорциональна произведению трех функций: плотностей занятых начальных $\rho_{s}\left(E_{t}\right)$ и пустых конечных $\rho_{f}\left(E_{t}\right)$ состояний на изоэнергетическом транспортном уровне $E_{t}$ и туннельной проницаемости $D\left(E_{t}\right)$ [9]:

$$
g_{\text {tun }} \equiv d I / d E_{t}=A D\left(E_{t}\right) \rho_{s}\left(E_{t}\right) \rho_{f}\left(E_{t}\right),
$$

здесь $A-$ постоянная величина.

Метод туннельной спектроскопии глубоких центров Эсаки [7] исходит из предположения, что ширина барьера в $p-n$-переходе определяется концентрацией основной легирующей примеси. Высота барьера уменьшается при прямом смещении: $\varphi=\varphi_{0}-V\left(\varphi_{0} / q-\right.$ контактная разность потенциалов), и проницаемость экспоненциально увеличивается с ростом смещения: $D \propto \exp \left(C_{1} V\right)$, где $C_{1}-$ константа. Поток основных носителей из разрешенной зоны туннелирует через барьер на менее легированной стороне перехода к границе $p-n$-перехода, где основные носители рекомбинируют с неосновными носителями, диффундирующими из противоположной стороны перехода. В результате больцмановского распределения по энергии свободных носителей основной поток туннелирует вблизи квазиуровня Ферми. Предполагается, что избыточный туннельный ток при заданном смещении растет линейно с увеличением плотности пустых конечных состояний с энергией $E_{t}$ на границе перехода $\rho_{f}\left(E_{t}\right)$ ( $E_{t}$ отсчитывется от уровня Ферми на границе перехода). Максимумы плотности состояний $\rho_{f}\left(E_{t}\right)$ проявляются как горбы туннельного тока на $I-V$-характеристиках.

В материалах с высокой плотностью локализованных состояний туннелирование носителей через потенциальный барьер можно рассматривать на основе модели дисперсионного транспорта [20,21]: носители на краю нейтральной области совершают туннельный переход в ближайший локальный центр, а более удаленных достигают путем прыжкового движения по центрам на туннельном транспортном уровне $E_{t}$. Частота перескоков и локальная туннельная проводимость, экспоненциально уменьшаются с увеличением расстояния между локальными центрами на уровне $E_{t}[21]$.

Отмеченная выше аналогичность формы $I-V$-характеристик наноструктуры А (рис. 3, $a$, кривая 1 ) и туннельных переходов позволяет предположить, что вследствие высокой плотности дефектов (учитывая их возможный сток на прорастающие дислокации и границы зерен), на периферии области объемного заряда (OO3) расстояние между локальными центрами (в слое толщиной $w-d$ на рис. 1) достаточно мало, чтобы обеспечить ее высокую туннельную проводимость. Основной вклад в туннельное сопротивление барьера $r=1 / g_{\text {tun }}$ дает туннельное сопротивление приграничного слоя (слоя толщиной $d$ на рис. 1) с наибольшей энергией локализации центров на туннельном транспортном уровне $E_{t}$. Приращение прямого смещения распределяется между $n$ - и $p$-барьерами пропорционально туннельным сопротивлениям их приграничных слоев $r_{n}$ и $r_{p}\left(r_{n}+r_{p}=r\right)$.
В $p$-n-структуре с квантовой ямой протекает туннельно-рекомбинационный ток: электроны и дырки туннелируют через барьеры и рекомбинируют в области объемного заряда. Непрерывность тока обеспечивается равенством туннельных потоков электронов и дырок. Центры окраски, подобно молекулярным комплексам, образуют примесные зоны в верхней и нижней половинах запрещенной зоны. Максимум или ступень тока возникает при таком прямом смещении $V \equiv F_{n}-F_{p}$, когда электронный уровень Ферми $F_{n}$ на границе между квантовой ямой и $n$-областью перехода окажется на уровне максимума плотности состояний примесной зоны центров окраски в верхней половине запрещенной зоны, а дырочный уровень Ферми $F_{p}$ в $p$-области - на уровне максимума плотности состояний примесной зоны этих центров в нижней половине запрещенной зоны. В случае $r_{n} \approx r_{p}$ приращение прямого смещения распределяется между $n$ - и $p$-барьерами поровну, и носители заряда рекомбинируют на границе перехода. В случае сильной асимметричности туннельных сопротивлений приращение смещения падает, в основном, на барьере с высоким туннельным сопротивлением $r_{\max }$, и носители рекомбинируют преимущественно в ООЗ этого барьера.

Анализ формы $I-V$-характеристик (рис. 2 и 3 ) приводит также к заключению, что плотность объемного заряда ионизованных примесных центров не является пренебрежимо малой по сравнению с плотностью основной легирующей примеси, и их объемный заряд оказывает существенное влияние на величину туннельной проницаемости приграничных слоев, управляя туннельными потоками в $p-n$-структуре.

Туннельная спектроскопия глубоких уровней дефектов. Горбы и ступени в туннельном спектре темнового тока $I(V)$ структуры А (рис. $3, a$, кривая 1 ) в интервалах смещений $V_{i}(i=1, \ldots, 7)$ отражают присутствие в запрещенной зоне $\mathrm{GaN}$ нескольких примесных зон гауссова типа $\rho_{i}(E)$ с максимумами плотности состояний при $E=E_{0 i}$, наложенных на непрерывный фон примесных состояний урбаховского хвоста $\rho_{U}(E)$, распространяющегося, экспоненциально убывая, вглубь запрещенной зоны.

По мере того, как с ростом прямого смещения транспортный уровень $E_{t}$ в барьере с $r_{\max }$ вблизи гетерограницы перемешается к краю разрешенной зоны, на характер изменения туннельной проводимости наиболее сильное влияние, согласно (2), оказывает изменение произведения двух функций $\rho_{f}\left(E_{t}\right) D\left(E_{t}\right)$, где $\rho_{f}\left(E_{t}\right)=\rho_{i f}\left(E_{t}\right)+\rho_{U f}\left(E_{t}\right)-$ суммарная плотность пустых конечных состояний примесной зоны и урбаховского хвоста с энергией $E_{t}, D\left(E_{t}\right)$ - туннельная проницаемость приграничного слоя:

$$
g_{t u n}\left(E_{t}\right) \propto D\left(\frac{d \rho_{i f}}{d E_{t}}+\frac{d \rho_{U f}}{d E_{t}}\right)+\left(\rho_{i f}+\rho_{U f}\right) \frac{d D}{d E_{t}} .
$$

Согласно (3), приращение плотности пустых конечных состояний $d \rho_{f}\left(E_{t}\right) / d E_{t}$ при перемещении уровня $E_{t}$ 
приводит к тем большему увеличению $g_{\text {tun }}$, чем выше проницаемость барьера. Но одновременное заполнение и перезарядка конечных состояний примесной зоны $\rho_{i}(E)$ ведет к уменьшению проницаемости, вплоть до изменения знака $g_{\text {tun }}$. Перезарядка глубоких состояний экспоненциального хвоста $\rho U\left(E_{t}\right)$ не приводит к существенному уменьшению $D\left(E_{t}\right)$, так как полный заряд его ионизованных состояний $Q_{U}$ определяется плотностью мелких состояний.

В структуре А максимум туннельного тока при $V_{p}=0.31 \mathrm{eV}$ вызван присутствием гауссовой примесной зоны $\rho_{1 f}\left(E_{t}\right)$. Относительный максимум при смещении $V=0.52 \mathrm{eV}$ можно связать с ростом плотности состояний примесного урбаховского хвоста $\rho_{U f}\left(E_{t}\right)$ на уровне $E_{t}$. Отрицательная дифференциальная проводимость $g_{\text {tun }}<0$ возникает в результате уменьшения туннельной проницаемости барьера с увеличением смещения, вызванного уменьшением суммарного объемного заряда ионизованных состояний примесных зон $Q_{G}\left(E_{t}\right)$ при перезарядке состояний $\rho_{1}(E)$ и $\rho_{2}(E)$. Последовательное уменьшение туннельной проницаемости $D\left(E_{t}\right)$ по мере роста смещения и перезарядки состояний $\rho_{i}(E)(i=2,3,4)$ уменьшает высоту токовых горбов в долине $I-V$-характеристики. Резкий ступенчатый рост туннельного тока в области смещений $V$ от 1.65 до $2.5 \mathrm{eV}$ обусловлен высокой плотностью состояний $\rho_{i}(E)(i=5,6,7)$.

В структуре В в области смещений, соответствующих долине $I-V$-характеристики в структуре А, наблюдается лишь слабая впадина на кривой $\lg I(V)$ (рис. $3, b$, кривая 1 ), что предполагает доминирующий вклад в величину объемного заряда в приграничном слое и его высокую туннельную проницаемость объемного заряда ионизованных состояний урбаховского хвоста $Q_{U}>Q_{G}\left(E_{t}\right)$.

Туннельная фотопроводимость ООЗ при подзонном возбуждении. При оптическом возбуждении происходит фотоионизация глубоких центров с энергией локализации $E_{l o c}>E_{t}$ и переход носителей заряда в разрешенную зону с последующим „вытягиванием“ носителей электрическим полем из ООЗ. Фотоиндуцированный объемный заряд $Q_{p h}$ суммируется с объемным зарядом, создаваемым тепловым возбуждением $Q_{t h}=Q_{G}\left(E_{t}\right)+Q_{U}$, что увеличивает напряженность поля в приграничном слое и его туннельную проницаемость $D\left(E_{t}\right)$.

В структуре А при низком уровне возбуждения (рис. 2, $a$, кривая 2) вблизи нулевого смещения $Q_{p h} / Q_{G}(0) \approx 1$. Увеличение отношения $Q_{p h} / Q_{G}\left(E_{t}\right)$ по мере перезарядки состояний примесных зон с ростом смещения ведет к росту $D\left(E_{t}\right)$ и $g_{t u n}$, более резкому на краях примесных зон при $E_{t}<E_{0 i}$, когда объемный заряд $Q_{G}\left(E_{t}\right)$ быстро уменьшается, и более слабому при $E_{t}>E_{0 i}$, когда уменьшение $Q_{G}\left(E_{t}\right)$ и $\rho_{f, i}\left(E_{t}\right)$ компенсируется ростом $\rho_{f, U}\left(E_{t}\right)$. Уменьшение проводимости $g_{\text {tun }}$ наблюдается лишь при малых смещениях, когда отношение $Q_{G}\left(E_{t}\right) / Q_{p h}$ еще достаточно высоко и преобладает вклад уменьшения объемного заряда $Q_{G}\left(E_{t}\right)$ на уровне $E_{t}$ в уменьшение проницаемости $D\left(E_{t}\right)$.
При возрастании уровня возбуждения $Q_{G}(0)<Q_{p h}$ и провалы светового тока $I_{\text {opt }}$ в области горбов темнового тока I (кривая 3) вызваны конкурирующим влиянием перезарядки состояний примесных зон и роста $\rho_{U}\left(E_{t}\right)$. Но при уменьшении отношения $Q_{G}\left(E_{t}\right) / Q_{p h}$ глубина модуляции туннельного тока объемным зарядом примесных зон с ростом смещения уменьшается и при высоком уровне возбуждения (при $Q_{G}(0) \ll Q_{p h}$, кривая 4) проявляется лишь в слабых осцилляциях туннельного тока со смещением.

В структуре В $Q_{U}>Q_{G}(0)$, и перезарядка состояний примесных зон не приводит к отрицательной дифференциальной проводимости, а лишь ограничивает рост тока, вызывая в туннельном спектре $\lg I_{\text {opt }}(V)$ при высоких уровнях возбуждения (рис. $3, b$, кривая 4 ) появление различимых ступеней: отсечки тока в области $E_{t}>E_{0 i}$ при $\rho_{f, i}\left(E_{t}\right)>\rho_{f, U}\left(E_{t}\right)$ и в области $E_{t}<E_{0 i}$ при $\rho_{f, i}\left(E_{t}\right)<\rho_{f, U}\left(E_{t}\right)$.

Фотостимулированная туннельная проницаемость стенок квантовой ямы. Фотоиндуцированный объемный заряд $Q_{p h}$ увеличивает туннельную проницаемость стенок ямы и приводит к ослаблению конфайнмента носителей и слабой фотолюминесценции из квантовой ямы при межзонном оптическом возбуждении. Последовательное заполнение и перезарядка состояний $\rho_{i}(E)$ в приграничном слое при увеличении смещения сопровождается уменьшением плотности объемного заряда $Q_{G}$ вблизи границы. Согласно (1), при заданной высоте барьера туннельная проницаемость стенки ямы экспоненциально уменьшается обратно пропорционально квадратному корню из величины плотности объемного заряда ионизованных примесей у гетерограницы: $D \propto \exp \left(-C_{2} / N_{t}^{1 / 2}\right)$, где $C_{2}$ - константа. Уменьшение туннельной проницаемости стенки ямы приводит к усилению конфайнмента оптически инжектированных носителей, проявляющегося в увеличении интенсивности ФЛ из квантовой ямы.

Чем больше энергия локализации носителей в квантовой яме и, соответственно, меньше энергия излучения, тем больше высота эффективного барьера, сквозь который носители туннелируют из квантовой ямы. Для глубоко локализованных носителей, ответственных за излучение на низкоэнергетичном крыле спектра, толщина потенциальной стенки вдоль пути туннелирования увеличивается сильнее. С ростом прямого смещения красное крыло спектра ФЛ растет значительно быстрее синего, что приводит к красному сдвигу пиковой энергии полосы ФЛ из квантовой ямы, сопровождающему увеличение интенсивности фотолюминесценции.

Природа центров, ответственных за туннельные токи утечки. Результаты туннельной спектроскопии глубоких центров коррелируют с известными данными оптических измерений в $\mathrm{GaN}$. Пороговое смещение $V=2.2 \mathrm{eV}$, при котором наблюдается резкое увеличение туннельного тока, соответствует пиковой энергии $h v_{p}=2.2 \mathrm{eV}$ полосы желтой ФЛ (YL) в GaN [1,22] и пороговой энергии $h v_{t h}$ поглощения YL-центрами окраски, ответственными за желтую ФЛ [23,24]. Увеличение туннельного 


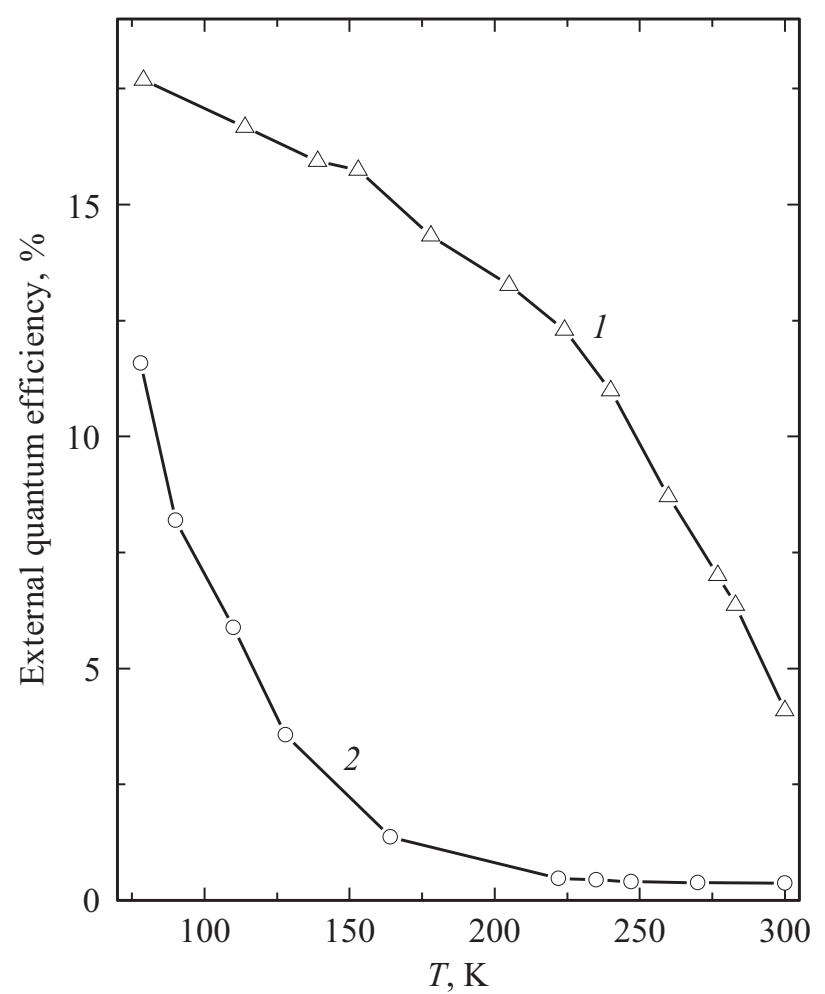

Рис. 5. Температурные зависимости квантовой эффективности электролюминесценции $\eta=I_{\mathrm{EL}} / I$ структур А (1) и В (2) при $I=3 v \mathrm{~A}$.

тока при смещении $V=2.4 \mathrm{eV}$ соответствует пиковой энергии $h v_{p}=2.4 \mathrm{eV}$ полосы зеленой ФЛ (GL) в $\mathrm{GaN}$ [22]. Область смещений $V$ от 1.65 до $2.2 \mathrm{eV}$ соответствует спектральной области поглощения RL-центрами окраски, ответственными за полосу красной ФЛ (RL) $\left(h v_{p}=1.85 \mathrm{eV}\right)$ и ее примесному урбаховскому хвосту, простирающемуся в ИК-область до $h v=1.65 \mathrm{eV}[1,25]$. Ряд токовых горбов в области смещений $0.7-1.65 \mathrm{eV}$ с примерно одинаковыми энергетическими интервалами между ними, предположительно, отражают серию полос в электронно-колебательной структуре кислородсодержащего дефекта. Токовые горбы с максимумами при $V \approx 1.25$ и $1.45 \mathrm{eV}$ соответствуют широкой полосе оптического поглощения с максимумом при $h v=1.22 \mathrm{eV}$, доминирующей в объемном $\mathrm{GaN}[13,23]$. Токовый горб с максимумом при $V \approx 0.8 \mathrm{eV}$ соответствует полосе ИК-фотолюминесценции в области $h v$ от 0.7 до $1 \mathrm{eV}$ с максимумами в окрестности 0.9 и $0.8 \mathrm{eV}$ [26] и пороговой энергии оптического поглощения в $\mathrm{GaN}$ $h v_{t h}=0.78 \mathrm{eV} \mathrm{[27].}$

Туннельные токи, протекающие при малых прямых смещениях „под“ квантовой ямой, уменьшают эффективность электролюминесценции при малых уровнях инжекции. Как видно из рис. 5, где представлены температурные зависимости квантовой эффективности $\eta=I_{\mathrm{EL}} / I\left(I_{\mathrm{EL}}-\right.$ интенсивность ЭЛ $)$ при токе $I=3 . \mu \mathrm{A}$, структуры А и В существенно отличаются не только величиной эффективности при комнатной температуре, но и ее температурной зависимостью, характеризующей температурное поведение туннельного тока утечки. Эффективность структуры А быстро увеличивается при охлаждении от 300 до $\sim 200 \mathrm{~K}$, и лишь слабо растет при охлаждении ниже $\sim 160 \mathrm{~K}$. В структуре В эффективность почти постоянна в интервале температур $300-200 \mathrm{~K}$ и быстро увеличивается при охлаждении от $\sim 160$ до $80 \mathrm{~K}$.

В структуре А с сильно легированной $p$-областью $\left(>3 \cdot 10^{18} \mathrm{~cm}^{-3}\right)$ характер туннельного токового спектра $I(V)$ в области смещений $2.2-2.5 \mathrm{eV}$ соответствует спектру $\Phi Л I_{\mathrm{PL}}(h v)$ слоев $p$-GaN с концентрацией дырок $\sim 10^{18} \mathrm{~cm}^{-3}$, характеризующемуся слабой ФЛ в ИК- и красной (RL) области спектра и более интенсивной полосой ФЛ в зеленой (GL) области $[1,22]$. Связь туннельных токов в области смещений $2.4-2.5 \mathrm{eV}$ ( $I$ меняется в интервале $2-10 \mu \mathrm{A}$ ) с плотностью GL-центров окраски в слое $p$-GaN подтверждается температурной зависимостью интенсивности GL ФЛ в слоях $p-\mathrm{GaN}$, увеличивающейся примерно на два порядка при охлаждении от 300 до $200 \mathrm{~K}$ [25], в том же температурном интервале, что и уменьшение туннельного тока (рис. 5 , кривая 1). Это позволяет связать уменьшение туннельной утечки и, соответственно, увеличение эффективности при охлаждении, с вымораживанием туннельной проводимости по GL-центрам окраски вследствие увеличения локализации дырок на этих центрах. Интервал температур 200-300 K характерен для размораживания подвижности молекулярного водорода, внедренного в металлы [28] или окислы [29], и возрастанию его химической активности. Это позволяет предположить вовлеченность молекулярного водорода в процесс формирования центров окраски, ответственных за низкие туннельные токи утечки.

Большие величины туннельных токов утечки в структуре В с относительно низкой концентрацией дырок $\left(\sim 2 \cdot 10^{17} \mathrm{~cm}^{-3}\right)$ в слое $p$-GaN можно связать с высокой плотностью RL-центров окраски, характерной, согласно данным ФЛ [1], для слоев $p-\mathrm{GaN}$ с недостаточной активацией $\mathrm{Mg}$-акцепторов и относительной высокой интенсивностью ФЛ в красной области и ближней ИК-области. Туннельный ток в области смещений $1.65-2.2 \mathrm{eV}$ (и токов 2-10 $\mu \mathrm{A}$ ), соответствующих RL-центрам окраски, уменьшается в интервале температур 150-80K (рис. 5, кривая 2), в котором наблюдается увеличение на два порядка интенсивности UVL-фотолюминесценции в GaN [30], связываемой с донорно-акцепторными парами, включающими атомы водорода. Интервал температур $80-150 \mathrm{~K}$ характерен для размораживания подвижности атомарного водорода. Это позволяет предположить вовлеченность слабосвязанного атомарного водорода в процесс формирования RL-комплексов, обусловливающих большие туннельные токи утечки, увеличение которых обычно наблюдается в процессе деградации светодиодных наноструктур на основе GaN. 


\section{4. Заключение}

Эффективность локализации в квантовой яме InGaN/GaN оптически инжектированных носителей ограничивается объемным зарядом термически и оптически ионизованных глубоких центров, увеличивающим напряженность электрического поля вблизи гетерограниц и туннельную проницаемость потенциальных стенок ямы, позволяя туннелирующим из квантовой ямы носителям генерировать фототок. При прямом смещении, приложенном к $p$-n-наноструктуре, напряженность электрического поля уменьшается преимущественно в стенках квантовой ямы, уменьшая их проницаемость. Уменьшение объемного заряда у гетерограниц по мере заполнения примесных зон глубоких центров окраски при прямом смещении отражается в ступенчатом уменьшении проницаемости стенок ямы и усилении конфайнмента носителей, что проявляется как ступенчатое увеличение интенсивности фотолюминесценции из квантовой ямы.

\section{Конфликт интересов}

Авторы заявляют, что у них нет конфликта интересов.

\section{Список литературы}

[1] S. Nakamura, G. Fasol. The Blue Laser Diode: GaN Based Light Emitters and Lasers. Springer, Berlin, N.Y. (1998). $343 \mathrm{p}$.

[2] D. Feezell, S. Nakamura. C.R. Phys. 19, 3, 113 (2018).

[3] C.H. Qiu, C. Hoggatt, W. Melton, M.W. Leksono, J.I. Pankove. Appl. Phys. Lett. 66, 20, 2712 (1995).

[4] P. Perlin, M. Osinski, P.G. Eliseev, V.A. Smagley, J. Mu, M. Banas, P. Sartori. Appl. Phys. Lett. 69, 12, 1680 (1996).

[5] J.R. Lang, N.G. Young, R.M. Farrell, Y.R. Wu, J.S. Speck. Appl. Phys. Lett. 101, 181105 (2012).

[6] H. Zhang, E.J. Miller, E.T. Yu. J. Appl. Phys. 99, 023703 (2006).

[7] Л. Эсаки. В сб.: Туннельные явления в твердых телах / Под ред. В.И. Переля. Мир, М. (1973). С. 51. [Tunneling phenomena in solids / Ed. E. Burstain, S. Lundqvist. Plenium Press, N. Y. (1969)].

[8] N. Holonyak. J. Appl. Phys. 32, 1, 130 (1961).

[9] A.G. Chynoweth, W.L. Feldmann, R.A. Logan. Phys. Rev. 121, 3, 684 (1961).

[10] А.А. Клочихин, С.А. Пермогоров, А.Н. Резницкий. ФТТ 39, 7, 1170 (1997)

[11] S.F. Chichibu, Y. Kawakami, T. Sota. In: Introduction to Nitride Semiconductor Blue Lasers and Light Emitting Diodes / Ed. S. Naramura, S.F. Chichibu. Taylor \& Francis, London-N.Y. (2000). 372 p.

[12] R.J. Molnar, T. Lei, T.D. Moustakas. Appl. Phys. Lett. 62, 1, 72 (1993).

[13] N.I. Bochkareva, A.M. Ivanov, A.V. Klochkov, Y.G. Shreter. J. Phys.: Conf. Ser. 1697, 012203 (2020).

[14] M.A. Reshchikov, H.J. Morkoç. Appl. Phys. 97, 061301 (2005).
[15] Y.T. Rebane, N.I. Bochkareva, V.E. Bougrov, D.V. Tarkhin, Y.G. Shreter, E.A. Girnov, S.I. Stepanov, W.N. Wang, P.T. Chang, P.J. Wang. Proc. SPIE 4996, 113 (2003).

[16] Л.В. Келдыш. ЖЭТФ 33, 4, 994 (1957); 34, 4, 962 (1958).

[17] S. Nakamura, M. Senoh, N. Iwasa, S. Nagahama, T. Yamada, T. Mukai. Jpn. J. Appl. Phys. Part 2 34, L1332 (1995).

[18] N.G. Young, R.M. Farrell, Y.L. Hu, Y. Terao, M. Iza, S. Keller, S.P. DenBaars, S. Nakamura, J.S. Speck. Appl. Phys. Lett. 103, 173903 (2013).

[19] N. Holonyak, Jr., D.L. Keune, R.D. Burnham, C.B. Duke. Phys. Rev. Lett. 24, 11, 589 (1970).

[20] N.F. Mott, E.A. Davis. Electronic processes in Non-Crystalline Materials. Clarendon Press, Oxford (1979).

[21] D. Monroe. Phys. Rev. Lett. 54, 2, 146 (1985).

[22] S.F. Chichibu, A. Uedono, K. Kojima, H. Ikeda, K. Fujito, S. Takashima, M. Edo, K. Ueno, S. Ishibashi. J. Appl. Phys. 123, 161413 (2018).

[23] Н.И. Бочкарева, И.А. Шеремет, Ю.Г. Шретер. ФТП 50, 10, 1387 (2016).

[24] D.M. Hofmann, D. Kovalev, G. Steude, B.K. Meyer, A. Hoffmann, L. Esckey, R. Heitz, T. Detchprom, H. Amano, I. Akasaki. Phys. Rev. B 52, 16702 (1995).

[25] M.A. Reshchikov, D.O. Demchenko, J.D. McNamara, S. Fernandes-Carrido, R. Calargo. Phys. Rev. B 90, 035207 (2014).

[26] E. Gaubas, P. Baronas, T. Čeponis, L. Deveikis, D. Dobrovolskas, E. Kuokstis, J. Mickevičius, V. Rumbauskas, M. Bockowski, M. Iwinska, T. Sochacki. Mater. Sci. Semicon. Proc. 91, 341 (2019).

[27] G. Yu, G. Wang, H. Ishikawa, M. Umeno, T. Soga, T. Egawa, J. Watanabe, T. Jimbo. Appl. Phys. Lett. 70, 24, 3209 (1997).

[28] Е.Г. Максимов, О.А. Панкратов. УФН 116, 3, 385 (1975).

[29] D.L. Gricom. J. Appl. Phys. 58, 7, 2524 (1985).

[30] M.A. Reshchikov, R.Y. Korotkov. Phys. Rev. B 64, 115205 (2001).

Редактор Е.Ю. Флегонтова 